\title{
Research on degradation of penicillins in milk by $\beta$-lactamase using ultra-performance liquid chromatography coupled with time-of-flight mass spectrometry
}

\author{
Lixin $\mathrm{Li}{ }^{*} \dagger$ Chunhai Guo, $\neq$ Lianfeng Ai, $\ddagger$ Caiyun Dou, $\ddagger$ Guizhen Wang, $\dagger$ and Hanwen Sun*1 \\ ${ }^{*}$ College of Chemistry and Environmental Science, Hebei University, Key Laboratory of Analytical Science and Technology of Hebei Province, \\ Baoding 071002, China \\ †Hebei Chemical \& Pharmaceutical College, Shijiazhuang 050026, China \\ †Hebei Entry-Exit Inspection and Quarantine Bureau, Shijiazhuang 050051, China
}

\begin{abstract}
The degradation of penicillin $\mathrm{G}$, penicillin $\mathrm{V}$, and ampicillin in milk in the presence of $\beta$-lactamase was investigated by ultra-performance liquid chromatography coupled with electrospray ionization-time-of-flight mass spectrometry. Degradation products of the 3 penicillins in milk were identified based on the fact that the metabolites or degradation products contain a substructure of penicillin, and their degradation pathways in acidic milk in presence of $\beta$-lactamase were developed. The influence of factors on the degradation was investigated, including $\beta$-lactamase dosage, temperature, time, and acidity. The ratio of the 2 degradation products (penicilloic acid and penilloic acid) is different at different temperatures and $\mathrm{pH}$. Penicilloic acid was the dominant species obtained at $\mathrm{pH} 6$ under $40^{\circ} \mathrm{C}$, but, being unstable, it could not be used as a standard for accurate analysis of penicilloic acid, and also could not be used as target for detection of penicillins in milk. Penilloic acid was the dominant species obtained at pH 2 above $40^{\circ} \mathrm{C}$; it was stable and could be used as a standard for quantitative analysis and as target for detecting whether penicillins were used in milk.
\end{abstract}

Key words: penicillin, degradation, milk, $\beta$-lactamase

\section{INTRODUCTION}

Penicillins are antibacterial agents belonging to the group known as the $\beta$-lactam antibiotics. As penicillin antibiotics have strong antimicrobial activities, they have been used extensively both in clinic and animal breeding practices. However, penicillins may cause allergic reactions, even death in some individuals. The use of penicillins in food-producing animals may lead to the emergence of penicillin-resistant bacterial strains, and the residues in milk and tissues are potential risks for

Received January 15, 2014.

Accepted March 10, 2014.

${ }^{1}$ Corresponding author: hanwen@hbu.cn individuals who are hypersensitive to penicillins. Some cases of allergic reactions after consumption of foods containing penicillin residues have been reported in the literature (Dayan 1993: Fagerquist et al., 2005). Because penicillin antibiotics are usually used in treating mastitis in cows, milk is the most frequently analyzed sample. Due to serious public health risks (Kindred and Hubbert, 1993; Shea 2003; Goldman 2004), the use of antibiotics in milk has been strictly controlled. For example, in the European Union, the maximum residue limit of antibiotics in milk powder, such as benzylpenicillin, ampicillin, and amoxicillin, is $4 \mu \mathrm{g} / \mathrm{kg}$ (EU Regulation 2377/90; EC, 1990). However, the continual abuse of penicillins in animal husbandry practices has been extensively documented (Marchetti et al., 2001). Penicillin antibiotics possess limited stability toward hydrolysis, leading to the formation of different degradation products. Some of the degradation products can cause allergic reactions in humans; thereby, they are a potential hazard to human health (Page, 1984; Deshpande et al., 2004; Zhang et al., 2010b). $\beta$-Lactamase could hydrolyze the $\beta$-lactam ring of the antibiotics and be used as an inhibitor in clinical practice. $\beta$-Lactamase residues in milk also represent a public health risk (Wang et al., 2013). Recently, it was used illegally as a milk additive to avoid penicillins added to milk being detected (Wang et al., 2013). Therefore, it is necessary to monitor the presence of penicillins and their degradation products for food safety.

A series of liquid chromatography (LC) methods have been used widely for the determination of penicillin antibiotics in milk (Daeseleire et al., 2000; Riediker and Stadler, 2001; Holstege et al., 2002; Ghidini et al., 2003; Riediker et al., 2004; Msagati and Nindi, 2007; Zhang et al., 2010a; Kukusamude et al., 2012; Lara et al., 2012). However, the accuracy of these methods needs to be improved due to target analytes being degraded in the sample preparation procedure. Few reports exist on the determination of degradation products/metabolites of penicillin antibiotics due to lack of stable standards of penicillin degradation products. 
Ultra-performance liquid chromatography/tandem mass spectrometry was used to determine some penicillins and their metabolites, such as amoxicillin and its major metabolites, in animal tissues (De Baere et al., 2002; Reyns et al., 2008), 2 penicillins and their 5 major metabolites in bovine muscle (Liu et al., 2011), a metabolite of cefapirin in milk (Zhu et al., 2010), penicillin $\mathrm{G}$ and penicilloic acid in milk (Feng et al., 2012b), 14 penicillins and penicilloic acids in milk (Feng et al., 2012a), and a degradation product of penicillin $\mathrm{G}$ in adulterated milk. ${ }^{10}$ The accuracy of some of these methods for using penicilloic acid as a standard needs to be improved due to instability of penicilloic acid. Otherwise, in the treatment process of milk samples, temperatures under $40-45^{\circ} \mathrm{C}$ caused further degradation of penicilloic acid. Up to now, to our knowledge, no report exists on studying enzyme degradation of penicillins in milk by $\beta$-lactamase and for accurately determining penicillins and their degradation products in milk.

The objective of this study was to investigate the effect of dosage, temperature, time, and $\mathrm{pH}$ on degradation of the penicillins in milk in the presence of $\beta$-lactamase, to identify degradation products of penicillin $\mathrm{G}$, penicillin $\mathrm{V}$, and ampicillin in milk by ultra-performance liquid chromatography coupled with electrospray ionization/ time-of-flight mass spectrometry (UPLC-ESI-TOFMS), and to select an appropriate degradation product that could be used a target for detection of penicillin in milk.

\section{MATERIALS AND METHODS}

\section{Instrumentation}

An Agilent 1200 liquid chromatography system and an Agilent 6224 time-of-flight mass spectrometer (Agilent Technologies Inc., Santa Clara, CA) with dual electrospray ionization source were used for liquid chromatography and spectrometry. Instruments used for sample preparation were as follows: SA300 Oscillator (Yamato Scientific Co. Ltd., Kanagawa, Japan), 8893 model ultrasonic cleaner (Cole-Parmer Co., Chicago, IL), EL131 rotary vacuum evaporator (Büchi Labortechnik AG, Flawil, Switzerland) with BP-51 vacuum cooling system, TGL-16M centrifuge (Xiangyi Centrifuge Co., Hunan, China), T25 homogenizer (IKA Labortechnik, Staufen, Germany), and Milli-Q highly pure water machine (Millipore Co., Billerica, MA).

\section{Chemicals and Reagents}

$\beta$-Lactamase was purchased from Beiwang Biological Technique Ltd. Co. (Hangzhou, China), and its stan- dard solution $\left(1 \times 10^{6} \mathrm{U} / \mathrm{mL}\right)$ was prepared before use. A stock standard solution of penicillin $\mathrm{G}$, penicillin $\mathrm{V}$, and ampicillin, $200 \mu \mathrm{g} / \mathrm{mL}$ for each, was prepared with its compound with acetonitrile/water (50:50, vol/vol). Acetonitrile and formic acid were HPLC grade.

\section{Conditions of UPLC-ESI-TOF-MS Analysis}

An Agilent SB- $\mathrm{C}_{18}$ column $(2.1 \times 100 \mathrm{~mm}$ i.d., $1.8-$ $\mu \mathrm{m}$ film thickness) and a mobile phase (acetonitrile containing $0.1 \%$ formic acid) were used for the separation of target analytes. Fifty microliters was injected into the UPLC-ESI-TOF-MS system. The gradient program for acetonitrile concentration used was as follows: $10 \%$ acetonitrile in the mobile phase from 0 to 2 min, increased from 10 to $60 \%$ from 2 to 5 min, held at $60 \%$ from 5 to 8 min, decreased from 60 to $10 \%$ from 8 to $8.1 \mathrm{~min}$, and held at $10 \%$ from 8.1 to $15 \mathrm{~min}$. The flow rate was $0.3 \mathrm{~mL} / \mathrm{min}$ and the sample volume was $10 \mu \mathrm{L}$.

Time-of-flight mass spectrometry with a dual electrospray source and positive ionization mode was used. The TOF-MS scan was performed in an $\mathrm{m} / \mathrm{z}$ range of 100 to 1,500 , with a scan time of $0.5 \mathrm{~s}$. The source parameters were as follows: capillary voltage: $3.5 \mathrm{kV}$, cone voltage: $25 \mathrm{~V}$, skimmer: $65 \mathrm{~V}$, nebulizer pressure: $0.2068 \mathrm{MPa}$, desolvation temperature: $350^{\circ} \mathrm{C}$, and desolvation gas: $480 \mathrm{~L} / \mathrm{h}$.

\section{$\beta$-Lactamase Dosage for Degradation of Penicillins in Milk}

Several blank milk samples spiked with $1 \mu \mathrm{g}$ of penicillin $/ \mathrm{mL}$ and different dosages of $\beta$-lactamase sat overnight at $20 \pm 0.2^{\circ} \mathrm{C}$. Two milliliters of the mixture was taken and $10 \mathrm{~mL}$ acetonitrile:water $(3: 1)$ was added to precipitate protein. The mixture was vortex mixed for $2 \mathrm{~min}$ and centrifuged at $3,050 \times g$ for $10 \mathrm{~min}$ at $20^{\circ} \mathrm{C}$, and then the supernatant $(5 \mathrm{~mL})$ was evaporated to dryness under a stream of nitrogen at $40^{\circ} \mathrm{C}$. The obtained residue was dissolved in $2 \mathrm{~mL}$ of water and filtered in turn using a $0.44-$ and $0.22-\mu \mathrm{m}$ mixed cellulose ester microporous filter membrane. The amount of residue of penicillins was determined to confirm the optimal dosage of $\beta$-lactamase for their complete degradation.

\section{Temperature and Time for Enzymatic Degradation}

Ten milliliters of blank milk samples spiked with 1 $\mu \mathrm{g}$ of penicillin $/ \mathrm{mL}$ and $10 \mathrm{U}$ of $\beta$-lactamase was transferred into a sample flask and then put rapidly into a sample chamber at $5^{\circ} \mathrm{C}$ in the liquid phase system to observe the degradation reaction. The temperature was 
increased from 5 to $40^{\circ} \mathrm{C}$ in $5^{\circ} \mathrm{C}$ increments; the sample flask was moved to a water bath in which the temperature increased from 45 to $70^{\circ} \mathrm{C}$ in $5^{\circ} \mathrm{C}$ increments. The relevant degraded solution obtained according to the method above was analyzed every $30 \mathrm{~min}$ to confirm the temperature for complete degradation of the penicillins, and to examine the effect of temperature on the ratio of degradation products.

\section{Effect of Milk Acidity on Degradation}

A 4-mL volume of blank milk and $25 \mu \mathrm{g}$ of each penicillin were added to a $50-\mathrm{mL}$ centrifugal tube, and the acidity of milk was adjusted to $\mathrm{pH} 2,3,4,5,6,7,8$, and 9 separately in 8 tubes, and set at $22 \pm 0.2^{\circ} \mathrm{C}$ for $3 \mathrm{~h}$. Acetonitrile:water (3:1) was added, and diluted to $25 \mathrm{~mL}$, and then the relevant degraded solutions obtained at different acidities were analyzed according to the method above to examine the acidity needed for complete degradation of the penicillins, and the effect of acidity on the ratio of degradation products.

\section{RESULTS AND DISCUSSION}

\section{Optimization of UPLC-ESI-TOF-MS Conditions}

A mobile phase of acetonitrile:water was compared with methanol:water for the separation of penicillin $\mathrm{G}$, penicillin $\mathrm{V}$, and ampicillin on an Agilent $\mathrm{SB}-\mathrm{C}_{18}$ column $(2.1 \times 100 \mathrm{~mm}$ i.d., $1.8-\mu \mathrm{m}$ film thickness $)$. The primary test showed that when using acetonitrile:water as a mobile phase, the separation effect and peak phase were better than when using methanol:water, due to methanol forming a peniciloic ester with penicillin. Because the penicillins are in ion form in aquatic solution, formic acid was added in the mobile phase to increase the analytes. The effects of different concentrations $(0.05,0.1,0.15$, and $0.2 \%)$ of formic acid on the separation were examined. Acetonitrile containing $0.1 \%$ formic acid was selected as the mobile phase for the separation of the 3 compounds and their metabolites, resulting in higher resolution and good peak shape. The effects of different proportions of acetonitrile in the mobile phase on the peak area and the retention time of the 3 analytes in an isocratic and gradient elution program were investigated. The isocratic elution program was unfavorable for the analysis. For the gradient elution program, it was favorable to use the gradient with $10 \%$ acetonitrile in the mobile phase from 0 to 2 min, increasing the concentration from 10 to $60 \%$ from 2 to $5 \mathrm{~min}$, holding it at $60 \%$ from 5 to $8 \mathrm{~min}$, decreasing the concentration from 60 to $10 \%$ from 8 to $8.1 \mathrm{~min}$, and holding it at $10 \%$ from 8.1 to $15 \mathrm{~min}$.
The separation of the penicillins and their degradation products (penicilloic acid and penilloic acid) was achieved. Typical total ion current chromatograms obtained from a spiked milk sample with analytes at a level of $50 \mathrm{ng} / \mathrm{mL}$ are illustrated in Figure 1.

The total ion current chromatogram is a summation of the ion signal generated by all the precursor-fragment ion transitions in a designated acquisition window. An acceptable baseline chromatographic separation was achieved in a 10-min time window for 8 target compounds monitored using the elution program described above. It can be noted that, although complete resolution was not obtained for some degradation products, including the isomer of ampicillin degradation products (penicilloic acid, penamaldic acid, 5R-penilloic acid, and 5S-penilloic acid), tandem mass spectrometry allowed the selective determination of these compounds, as unique transitions were monitored.

Time-of-flight-mass spectrometry was combined with LC to identify the penicillins and their metabolites. Identifications were based on the fact that the metabolites or degradation products contain a substructure of penicillin (Suwanrumpha and Freast, 1989). To select the most sensitive ion pairs, a full-scan mass scan was first applied to identify the precursor ions by direct flow injection. Negative ion mode and positive ion mode were compared under multiple reaction monitoring (MRM) mode. The $[\mathrm{M}+\mathrm{H}]^{+}$ions were found to be the most abundant and were selected as precursor ions. The $[\mathrm{M}+\mathrm{H}]^{+}$ions and product ions were observed, as shown in Figure 2, and retention time, molecular formula, molecular weight, $[\mathrm{M}+\mathrm{H}]^{+}$ions and ion pairs of penicillin and their degradation products are listed in Table 1.

The $[\mathrm{M}+\mathrm{H}]^{+}$ions at $m / z 335.1051,351.1005$, and 350.1150 for penicillin $\mathrm{G}$, penicillin $\mathrm{V}$, and ampicillin show that the fragmentation of penicillins was the result of the opening and cleavage of the $\beta$-lactam ring. Therefore, fragmentation of penicillins produced the class-specific ion product $\left[\mathrm{C}_{6} \mathrm{H}_{9} \mathrm{NO}_{2} \mathrm{~S}+\mathrm{H}\right]^{+}$at $\mathrm{m} / z$ 160. Due to the loss of $\mathrm{HCOOH}$ from the ion product $\left[\mathrm{C}_{6} \mathrm{H}_{9} \mathrm{NO}_{2} \mathrm{~S}+\mathrm{H}\right]^{+}$at $m / z$ 160, fragmentation of the 3 penicillins produced the product at $m / z 114$, and penicillin $\mathrm{G}$, penicillin $\mathrm{V}$, and ampicillin exhibited the ion products at $m / z 176,192$, and 191 , respectively, corresponding to the loss of $\mathrm{C}_{6} \mathrm{H}_{9} \mathrm{NO}_{2} \mathrm{~S}$ from the precursor ion. The ion pairs used for quantification were $\mathrm{m} / \mathrm{z}$ $335 / 160,351 / 192$ and 350/114, respectively.

The penicillins could be converted to penicilloic acid in the presence of $\beta$-lactamases. The signals of the 3 protonated penicilloic acids for penicillin $\mathrm{G}$, penicillin $\mathrm{V}$, and ampicillin were clearly observed as a peak at $m / z$ 353.1158, 369.1109, and 368.1270, respectively. 


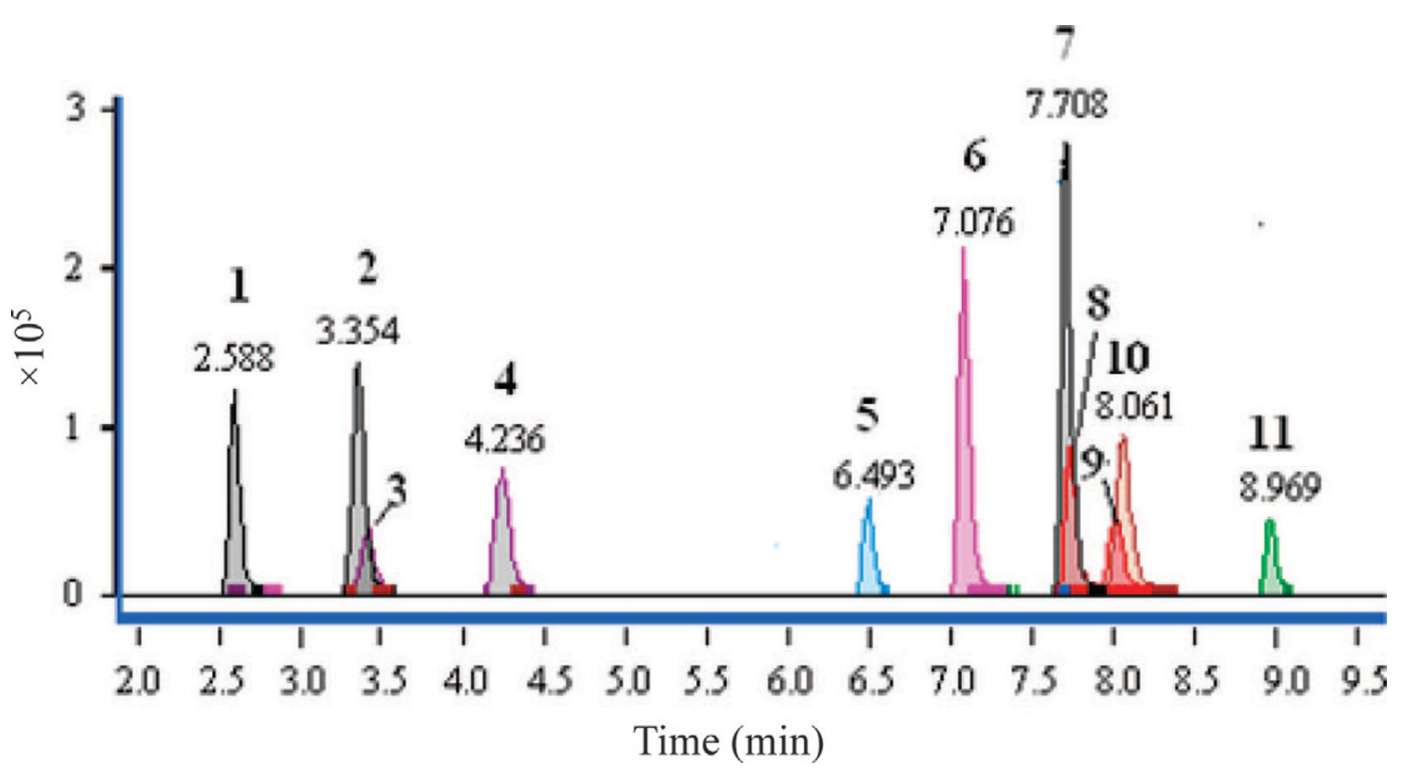

Figure 1. Total ion current chromatograms monitored for the penicillins and their degradation products in milk $1=$ ampicillin penicilloic acid; $2=$ ampicillin penamaldic acid; $3=$ ampicillin 5R-penilloic acid; $4=$ ampicillin 5 S-penilloic acid; $5=$ ampicillin; $6=$ penicillin $\mathrm{G} ; 7=$ penicilloic $\mathrm{G}$ acid; $8=$ penilloic $\mathrm{G}$ acid; $9=$ penicilloic $\mathrm{V}$ acid; $10=$ penilloic $\mathrm{V}$ acid; $11=$ penicillin $\mathrm{V}$. Color version available in the online PDF.

Fragmentation of penicilloic acid produced the classspecific ion product $\left[\mathrm{C}_{6} \mathrm{H}_{9} \mathrm{NO}_{2} \mathrm{~S}+\mathrm{H}\right]^{+}$at $m / z 160$. The fragmentation of the 3 penicilloic acids produced the product at $m / z 114$ due to the loss of $\mathrm{HCOOH}$ from the ion product $\left[\mathrm{C}_{6} \mathrm{H}_{9} \mathrm{NO}_{2} \mathrm{~S}+\mathrm{H}\right]^{+}$, and exhibited the ion products at $m / z 194,210$, and 209 , respectively, corresponding to the loss of $\mathrm{C}_{6} \mathrm{H}_{9} \mathrm{NO}_{2} \mathrm{~S}$ from the precursor ion (Cha et al., 2006). Additionally, a signal at $m / z 309$ could also be observed due to the loss of $\mathrm{CO}_{2}$ from the precursor ion (Xu et al., 2010). The ion pairs of $\mathrm{m} / \mathrm{z}$ $353 / 160,369 / 210$ and $368 / 209$, respectively, could be used for quantification.

In the presence of $\beta$-lactamases, the penicilloic acid was further converted to penilloic acid. The signals of the 3 protonated penilloic acid for penicillin $\mathrm{G}$, penicillin $\mathrm{V}$, and ampicillin were clearly observed as a peak at $m / z$ 309.1253, 325.1205, and 324.1370, respectively. The fragmentation of penicilloic acid produced the class-specific ion product $\left[\mathrm{C}_{6} \mathrm{H}_{9} \mathrm{NO}_{2} \mathrm{~S}+\mathrm{H}\right]^{+}$at $m / z 160$. Fragmentation of the 3 penicilloic acids produced the product at $\mathrm{m} / z 114$ due to the loss of $\mathrm{HCOOH}$ from the ion product $\left[\mathrm{C}_{6} \mathrm{H}_{9} \mathrm{NO}_{2} \mathrm{~S}+\mathrm{H}\right]^{+}$, and exhibited the ion products at $m / z 150,166$, and 165 , respectively, corresponding to the loss of $\mathrm{C}_{6} \mathrm{H}_{9} \mathrm{NO}_{2} \mathrm{~S}$ from the precursor ion. In this work, the $[\mathrm{M}+\mathrm{H}]^{+}$ions of $m / z 309,325$, and 324 , respectively, were used for quantification.

In addition, it is shown from the $m / z$ values of $[\mathrm{M}+\mathrm{H}]^{+}$ in Table 1 that the molecular weights calculated based on $m / z$ values of $[\mathrm{M}+\mathrm{H}]^{+}$ions for the penicillins, penicilloic acids, and penilloic acids were consistent with their theoretical molecular weights. The result shows that penicilloic acid and penilloic acid were the uppermost metabolites of penicillins present in the spiked milk in the presence of $\beta$-lactamases.

\section{Degradation Pathways of Penicillins in Milk}

The pathways of degradation of penicillins in acidic milk in presence of $\beta$-lactamase are shown in Figure 3. Penicillin is a unique molecule containing unstable, a highly strained and reactive $\beta$-lactam amide bond. The degradation of penicillin takes place in various conditions (namely, alkaline or acidic) in the presence of the enzyme $\beta$-lactamase or treatment of weak nucleophiles such as water and metal ions (Deshpande et al., 2004).

The enzyme opens the ring in the same way as acid hydrolysis does. 5R-Penicilloic acid is the first degradation product of penicillin and subsequently undergoes epimerization at $\mathrm{C}-5$ to form the $5 \mathrm{~S}$ isomer (penamaldic acid) via the imine tautomer. Penicilloic acid is stable in the form of salts or esters in neutral solutions, but on acidification, it readily loses 1 molecule of carbon dioxide, giving the corresponding penilloic acid (Hou and Poole, 1971).

Loss of 1 molecule of carbon dioxide at C- 6 removes 1 of the molecule's chiral centers. Nevertheless, the center at C-5 remains intact and, therefore, 2 isomers can be found: 5R-penilloic acid and 5s-penilloic acid (Suwanrumpha and Freast, 1989). In strong acid medium (pH 2 or less), penicillins are isomerized to penilloic acid by a mechanism involving the transient oxazolone structure (Blaha et al., 1976). 
Table 1. Retention time (RT), molecular formula, molecular weight, $[\mathrm{M}+\mathrm{H}]^{+}$ions of penicillin and their degradation products

\begin{tabular}{lclcc}
\hline Compound & $\begin{array}{c}\mathrm{RT} \\
(\mathrm{min})\end{array}$ & $\begin{array}{l}\text { Molecular } \\
\text { formula }\end{array}$ & $\begin{array}{c}\text { Molecular } \\
\text { weight }\end{array}$ & $\begin{array}{c}{[\mathrm{M}+\mathrm{H}]^{+}} \\
(\mathrm{m} / z)\end{array}$ \\
\hline Penicillin G & 7.076 & $\mathrm{C}_{16} \mathrm{H}_{18} \mathrm{~N}_{2} \mathrm{O}_{4} \mathrm{~S}$ & 334.39 & 335.1051 \\
Penicilloic G acid & 7.708 & $\mathrm{C}_{16} \mathrm{H}_{20} \mathrm{~N}_{2} \mathrm{O}_{5} \mathrm{~S}$ & 352.405 & 353.1158 \\
Penilloic G acid & 7.756 & $\mathrm{C}_{15} \mathrm{H}_{20} \mathrm{~N}_{2} \mathrm{O}_{3} \mathrm{~S}$ & 308.405 & 309.1253 \\
Penicillin V & 8.969 & $\mathrm{C}_{16} \mathrm{H}_{18} \mathrm{~N}_{2} \mathrm{O}_{5} \mathrm{~S}$ & 350.38 & 351.1005 \\
Penicilloic V acid & 7.890 & $\mathrm{C}_{16} \mathrm{H}_{20} \mathrm{~N}_{2} \mathrm{O}_{6} \mathrm{~S}$ & 368.405 & 369.1109 \\
Penilloic V acid & 8.061 & $\mathrm{C}_{15} \mathrm{H}_{20} \mathrm{~N}_{2} \mathrm{O}_{4} \mathrm{~S}$ & 324.405 & 325.1205 \\
Ampicillin & 6.493 & $\mathrm{C}_{16} \mathrm{H}_{19} \mathrm{~N}_{3} \mathrm{O}_{4} \mathrm{~S}$ & 349.4 & 350.1150 \\
Ampicillin penicilloic acid & 2.588 & $\mathrm{C}_{16} \mathrm{H}_{21} \mathrm{~N}_{3} \mathrm{O}_{5} \mathrm{~S}$ & 367.4 & 368.1270 \\
Ampicillin 5S-penilloic acid & 4.236 & $\mathrm{C}_{15} \mathrm{H}_{21} \mathrm{~N}_{3} \mathrm{O}_{3} \mathrm{~S}$ & 323.4 & 324.1370 \\
\hline
\end{tabular}
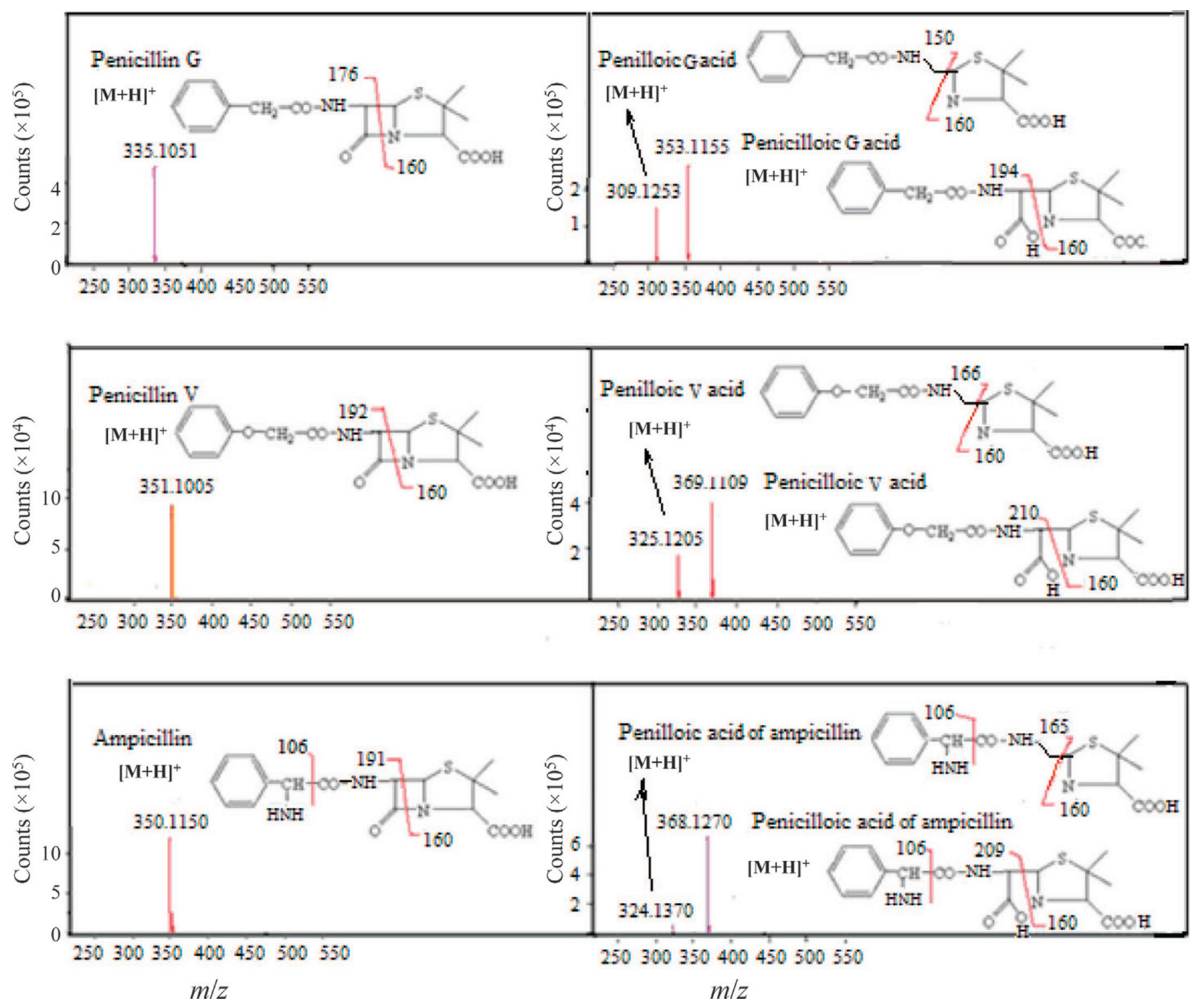

Figure 2. Precursor ions of the intact drugs (left) along with the precursors of the degradation products (right). Color version available in the online PDF. 


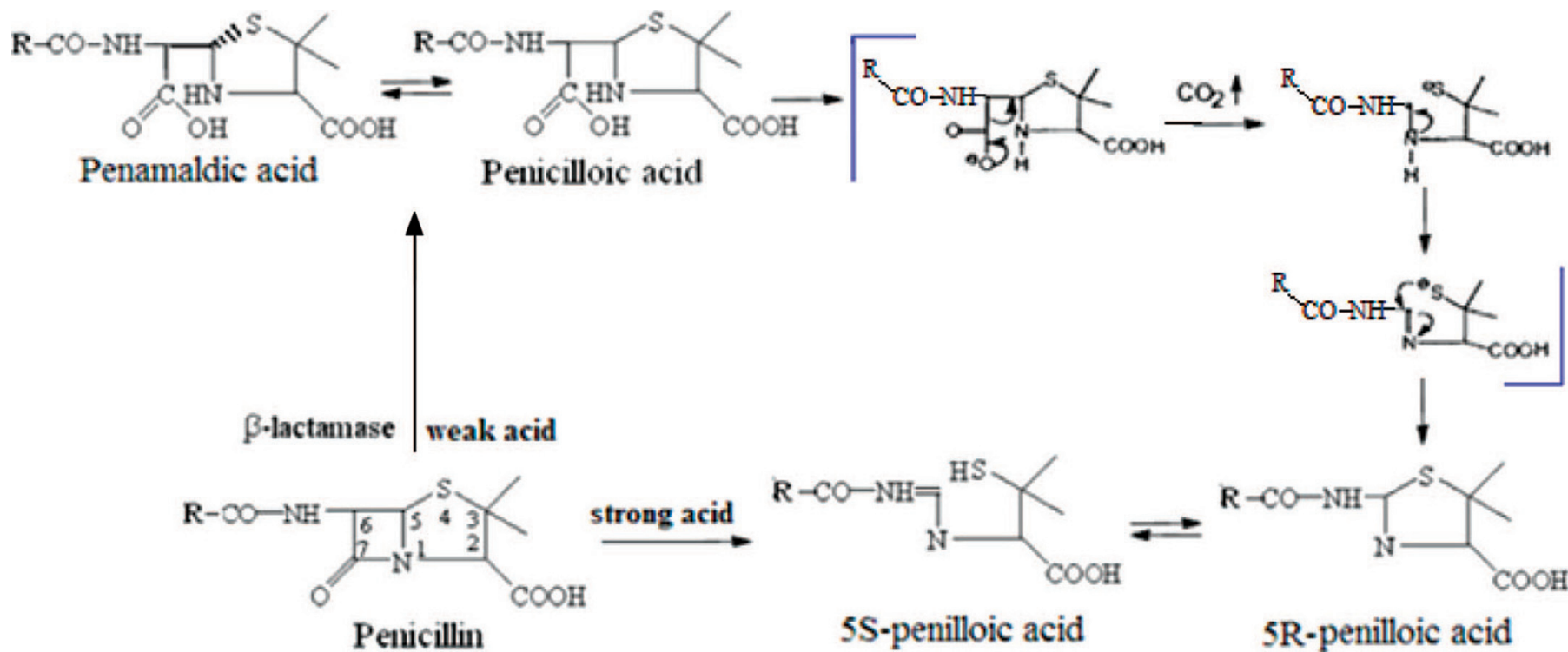

Figure 3. Degradation pathways of penicillins in milk in the presence of $\beta$-lactamase. Color version available in the online PDF.

\section{Effect of $\beta$-Lactamase Dosage on Enzyme Degradation}

The $\beta$-lactamase dosage that could cause penicillins to be degraded completely was investigated by using a $10-\mathrm{mL}$ volume of milk spiked with different contents of penicillin $(0.01,1.00,2.00,5.00$, and $10 \mathrm{mg})$. The $\beta$-lactamase dosage for complete degradation increased with increasing penicillin concentrations from 1 to 200 $\mu \mathrm{g} / \mathrm{mL}$, and increased slightly with penicillin concentrations from 200 to $1,000 \mu \mathrm{g} / \mathrm{mL}$. Figure 4 shows the effect of $\beta$-lactamase dosage on penicillin signal. The $\beta$-lactamase dosage for complete degradation of $1 \mu \mathrm{g}$ of penicillin/mL in $10 \mathrm{~mL}$ of milk was $10 \mathrm{U}$ for penicillin $\mathrm{G}$ and penicillin $\mathrm{V}$, and $11 \mathrm{U}$ for ampicillin.

The stability of penicillin in aqueous solution decreases with increasing temperature for all $\mathrm{pH}$ values (Kheirolomoom et al., 1999). The combined effects of temperature and time on complete enzymatic degradation of penicillin in milk by $\beta$-lactamase and the loss of penicillin with time at 20,30 , and $40^{\circ} \mathrm{C}$ were investigated.

Figure 5A shows a similar trend for complete-degradation time of the penicillins with temperature, and Figure 5B shows the loss curves of penicillin with time at 20,30 , and $40^{\circ} \mathrm{C}$. The degradation time was longer when the temperature was lower than $15^{\circ} \mathrm{C}$ because of lower enzymatic activity. When the temperature increased from 5 to $20^{\circ} \mathrm{C}$, the complete-degradation time decreased; the stability of penicillin in milk decreased with increasing temperature because increased temperature accelerated the rate of degradation of penicillin. The shortest time for complete degradation was $1.5 \mathrm{~h}$ at 20 to $35^{\circ} \mathrm{C}$ for ampicillin, $2 \mathrm{~h}$ at 20 to $35^{\circ} \mathrm{C}$ for penicillin $\mathrm{G}$, and $2.5 \mathrm{~h}$ at 20 to $40^{\circ} \mathrm{C}$ for penicillin $\mathrm{V}$; this shows that the rate of degradation of penicillins was maintained constant. When over $40^{\circ} \mathrm{C}$, the degradation time is longer because of self-degradation of $\beta$-lactamase (Deshpande et al., 2004).

\section{Effect of $\mathrm{pH}$ on Degradation of Penicillins in Milk}

The stability analysis shows that penicillin $\mathrm{G}$ is more stable at the $\mathrm{pH}$ range of 5.0 to 8.0 , and the maximum stability of penicillin $\mathrm{G}$ is at about pH 6.0 (Kheirolo-

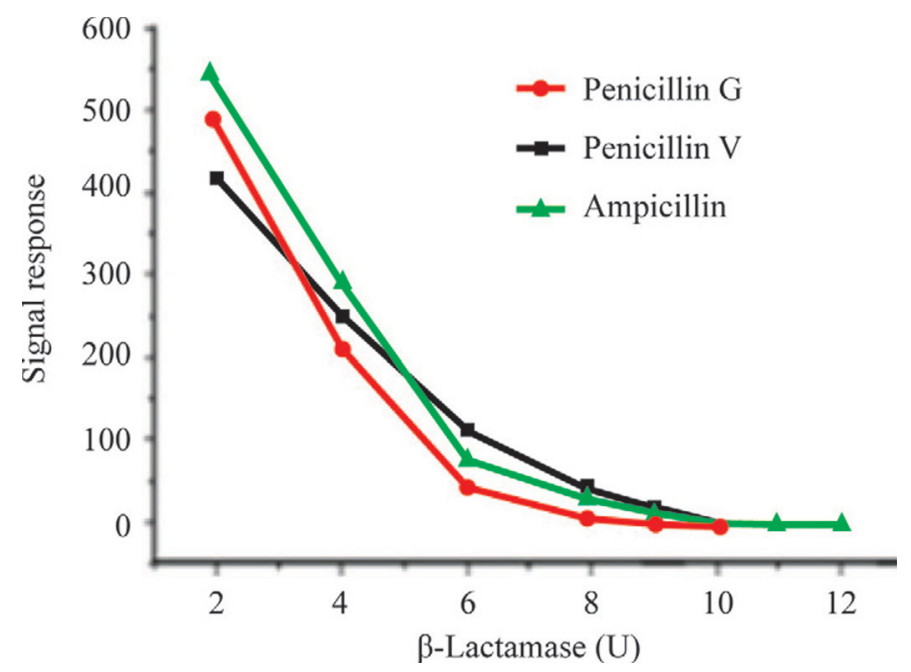

Figure 4. Effect of different dosages of $\beta$-lactamase on the signal response of $10 \mu \mathrm{g}$ of penicillin in $10 \mathrm{~mL}$ of milk. Color version available in the online PDF. 

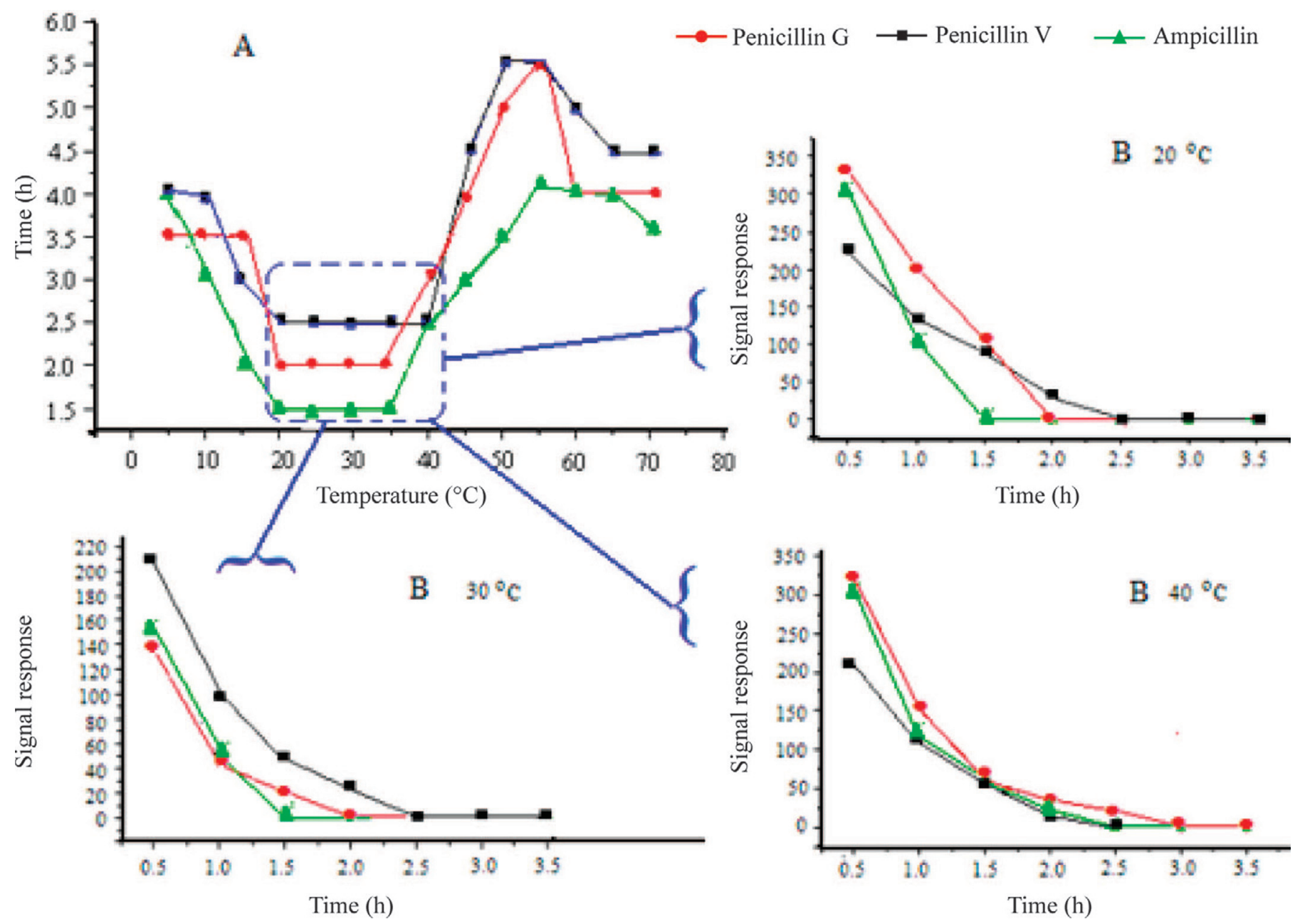

Figure 5. Temperature-time curves for complete degradation (A) and loss curves (B) of penicillins: $10 \mu \mathrm{g}$ of each in $10 \mathrm{~mL}$ of milk with 11 $\mathrm{U}$ of $\beta$-lactamase. Color version available in the online PDF.

moom et al., 1999). The half-life of penicillin $\mathrm{G}$ is 5 min at $\mathrm{pH} 2$, and the half-life of penicillin $\mathrm{V}$ is $5 \mathrm{~h}$ at $\mathrm{pH}$ 1. Ampicillin in aqueous solution has a $\mathrm{pH}$ of about 8. Cow milk has a $\mathrm{pH}$ ranging from 6.4 to 6.8 . In this work, the effects of milk pH from 2 to 9 on penicillin degradation in the absence and presence of $\beta$-lactamase were investigated, as shown in Figure 6.

Figure $6 \mathrm{~A}$ shows that penicillin $\mathrm{G}$, penicillin $\mathrm{V}$, and ampicillin are more stable at the $\mathrm{pH}$ range of 5.0 to 8.0, and their maximum stability is at about $\mathrm{pH} 6.0$. When $\mathrm{pH}$ decreased from 5 to 2 or increased from 8 to 9 , their stability decreased obviously. Figure $6 \mathrm{~B}$ shows that at $\mathrm{pH} \leq 3$, the stability of ampicillin was much higher than penicillin $\mathrm{G}$ and penicillin $\mathrm{V}$, and penicillin $\mathrm{G}$ was degraded almost entirely. At $\mathrm{pH}=4$, penicillin $\mathrm{V}$ was degraded almost entirely. At $\mathrm{pH} \geq 6$, the 3 penicillins were degraded completely. These results suggest that the presence of $\beta$-lactamase caused 3 penicillins in cow milk not be detected because the $\mathrm{pH}$ of milk ranged from 6.4 to 6.8 .

\section{Effect of Temperature on Degradation of Penicilloic Acid in Milk}

Cleavage of $\beta$-lactam amide bonds takes place in water when it is heated, but this cleavage is slower than that of $\beta$-lactamase inhibitors (Deshpande et al., 2004). In this work, at different temperatures, the response of 2 degradation products (penicilloic acid and penilloic acid) of penicillins in milk with $\beta$-lactamase was detected by UPLC-ESI-TOF-MS, as shown in Figure 7.

When the temperature was in the range of 5 to $40^{\circ} \mathrm{C}$, penicilloic acid was the primary degradation product of penicillins, and the temperature did not influence the degree of degradation. When the temperature increased from 40 to $65^{\circ} \mathrm{C}$, the proportion of penicilloic 


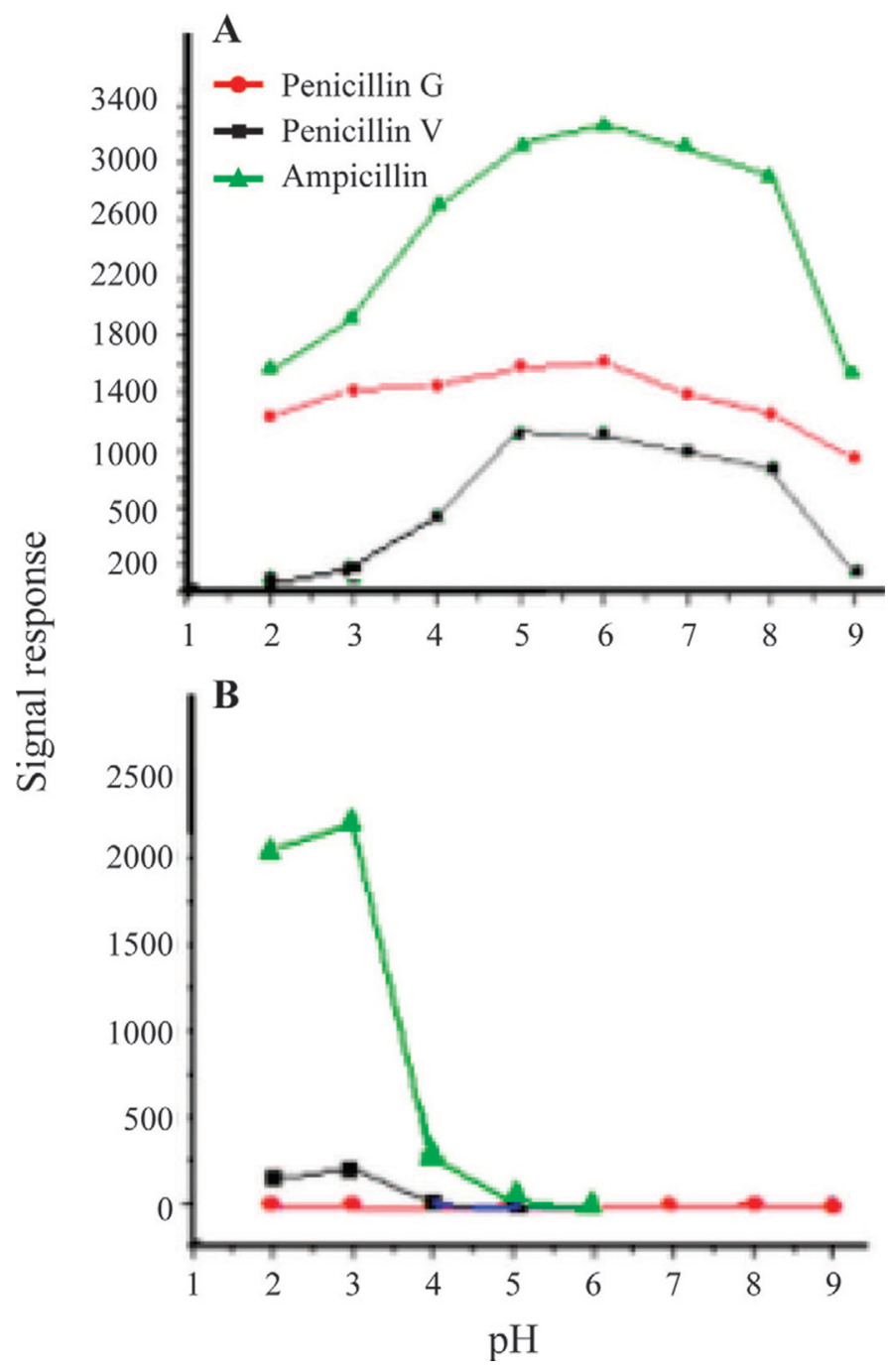

Figure 6. Effect of different $\mathrm{pH}$ on signal responses of penicillins in milk in the absence (A) and presence (B) of $\beta$-lactamase $(25 \mu \mathrm{g}$ each of penicillin $\mathrm{G}$, penicillin $\mathrm{V}$, and ampicillin; $30 \mathrm{U}$ of $\beta$-lactamase; $25^{\circ} \mathrm{C}$ enzyme degradation temperature; 3 -h enzyme degradation time). Color version available in the online PDF.

acid decreased markedly, and penilloic acid gradually became the primary degradation product. This occurred because the decarboxylation of penicilloic acid formed penilloic acid, but not because of enzymatic degradation. When the temperature was 65 to $70^{\circ} \mathrm{C}$, no penicilloic acid was detected. Therefore, the composition of degradation products of penicillins in milk with $\beta$-lactamase is dependent on temperature.

\section{Effect of $\mathrm{pH}$ on Degradation of Penicilloic Acid in Milk}

Effect of different $\mathrm{pH}$ of milk on the 2 degradation products (penicilloic acid and penilloic acid) in the absence and presence of $\beta$-lactamase was further exam- ined by UPLC-ESI-TOF-MS. Figure $8 \mathrm{~A}$ shows that in the absence of $\beta$-lactamase, penicilloic acid from the 3 penicillins was the most stable in the range of $\mathrm{pH} 2$ to 8. The stability of penilloic acid decreased with increasing $\mathrm{pH}$ from 2 to 5 , and the response tended to be more stable and weak. Figure $8 \mathrm{~B}$ shows that when increasing $\mathrm{pH}$ from 2 to 6 and in the presence of $\beta$-lactamase, the response of penicilloic acid from the 3 penicillins increased obviously, and the response of penilloic acid decreased. When increasing $\mathrm{pH}$ from 6 to 9, the response for penicilloic acid from ampicillin tended to be more stable than penicilloic acid from penicillin $G$, and the response for penicilloic acid from penicillin $\mathrm{V}$ decreased markedly. Otherwise, when increasing $\mathrm{pH}$ from 7 to 9 , the response of penilloic acid tended toward stability, such that when $\mathrm{pH}=6$, penicilloic acid from the 3 penicillins had maximal response, and when $\mathrm{pH}=$ 2, 3 penilloic acids from the 3 penicillins had maximal response.

\section{CONCLUSIONS}

The 3 penicillins in milk were degraded by $\beta$-lactamase to their penicilloic and penilloic acids. The enzymatic degradation was influenced by many factors, including $\beta$-lactamase dosage, temperature, time, and acidity. The ratio of the 2 degradation products was different with different temperatures and $\mathrm{pH}$. The choice of representative enzymatic degradation products of the 3 penicillins in milk by $\beta$-lactamase is necessary for detecting whether penicillins were used in milk. Among the penicillin degradation products in milk with

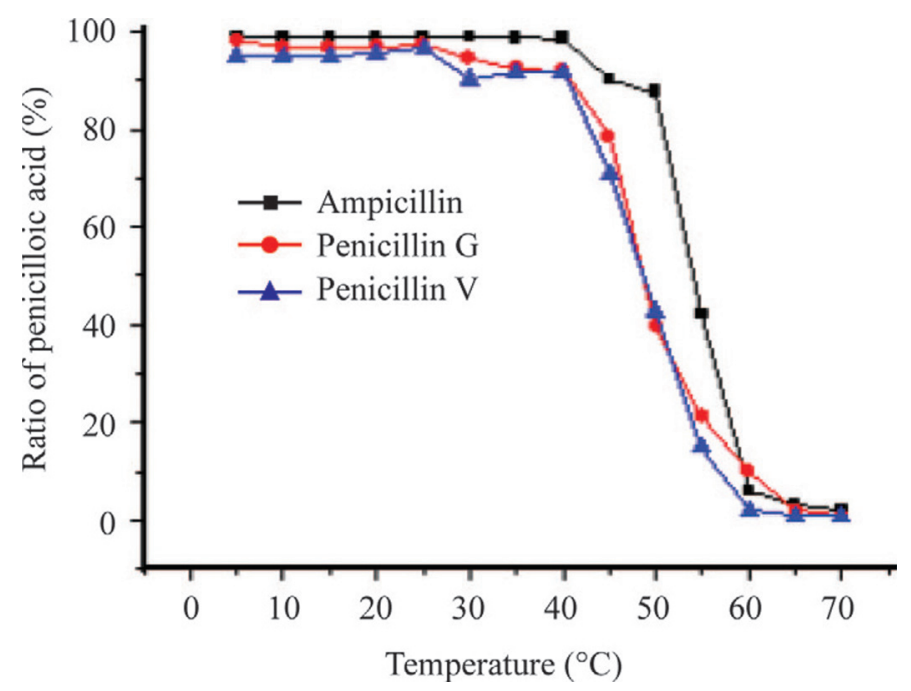

Figure 7. Effect of temperature on the ratio of penicilloic acid to penilloic acid in degradation products of penicillins in milk with $\beta$-lactamase $(25 \mu \mathrm{g}$ of each penicillin; $28 \mathrm{U}$ of $\beta$-lactamase; 3 -h enzyme degradation time). Color version available in the online PDF. 


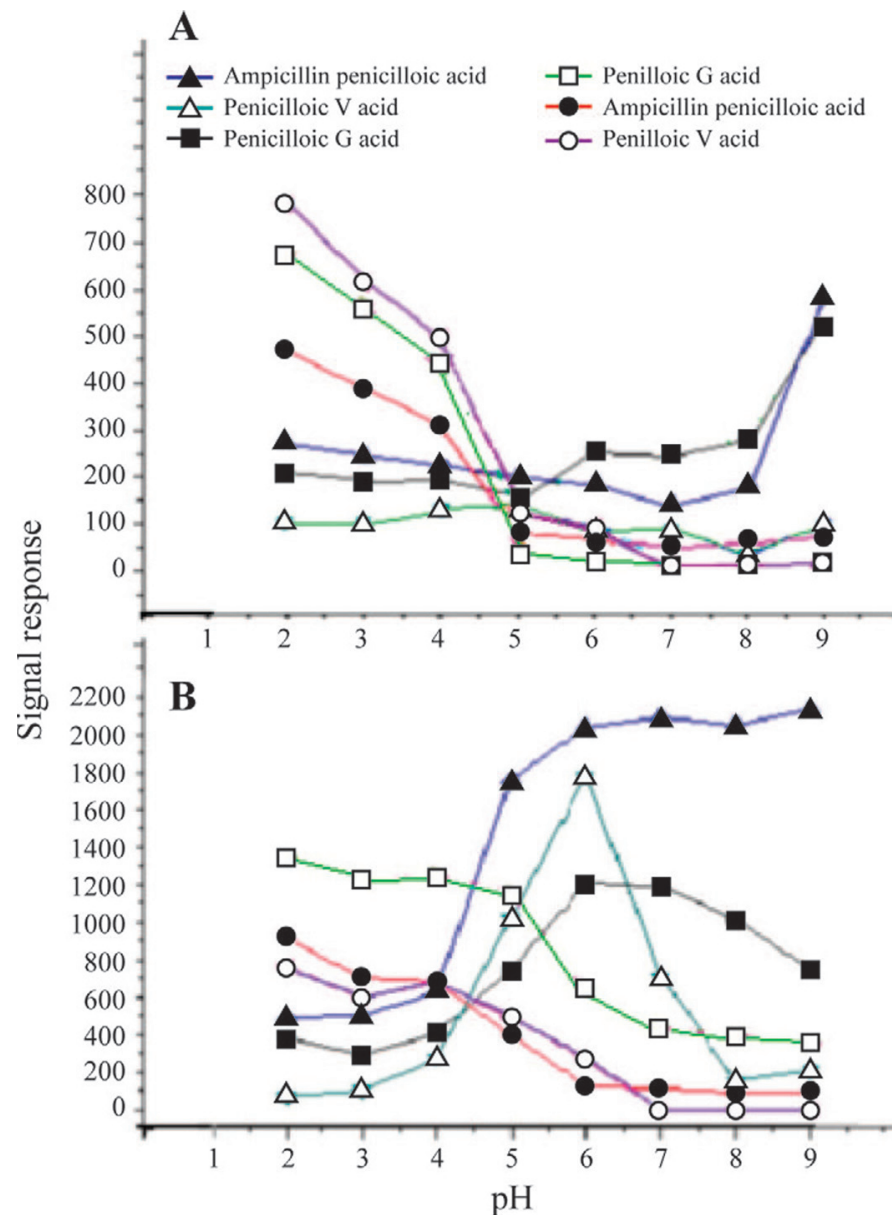

Figure 8. Effect of $\mathrm{pH}$ on signal intensity of penicilloic acid and penilloic acid produced in milk in the absence (A) and presence (B) of $\beta$-lactamase $(25 \mu \mathrm{g}$ each of penicillin $\mathrm{G}$, penicillin $\mathrm{V}$, and ampicillin; 32 $\mathrm{U}$ of $\beta$-lactamase; $25^{\circ} \mathrm{C}$ enzyme degradation temperature; 3 -h enzyme degradation time). Color version available in the online PDF.

$\beta$-lactamase, penicilloic acid was the dominant species obtained at $\mathrm{pH} 6$ under $40^{\circ} \mathrm{C}$, but it was unstable, so it could not be used as a standard for accurate analysis of penicilloic acid, and also could not be used as target for detection of penicillins in milk. Penilloic acid was the dominant species obtained at $\mathrm{pH} 2$ above $40^{\circ} \mathrm{C}$; it was stable and could be used as a standard for quantitative analysis and as a target for detecting wether penicillins were used in milk.

\section{REFERENCES}

Blaha, J. M., A. M. Knevel, D. P. Kessler, J. W. Mincy, and S. L. Hem. 1976. Kinetic analysis of penicillin degradation in acidic media. J. Pharm. Sci. 65:1165-1170.

Cha, J. M., S. Yang, and K. H. Carlson. 2006. Trace determination of $\beta$-lactam antibiotics in surface water and urban wastewater using liquid chromatography combined with electrospray tandem mass spectrometry. J. Chromatogr. A 1115:46-57.

Daeseleire, E., H. De Ruyck, and R. Van Renterghem. 2000. Confirmatory assay for the simultaneous detection of penicillins and cephalosporins in milk using liquid chromatography/tandem mass spectrometry. Rapid Commun. Mass Spectrom. 14:1404-1409.

Dayan, A. D. 1993. Allergy to antimicrobial residues in food: Assessment of the risk to man. Vet. Microbiol. 35:213-226.

De Baere, S., M. Cherlet, K. Baert, and P. De Backer. 2002. Quantitative analysis of amoxycillin and its major metabolites in animal tissues by liquid chromatography combined with electrospray ionization tandem mass spectrometry. Anal. Chem. 74:1393-1401.

Deshpande, A. D., K. G. Baheti, and N. R. Chatterjee. 2004. Degradation of $\beta$-lactam antibiotics. Curr. Sci. 87:1684-1695.

EC (European Commission). 1990. Community procedure for the establishment of maximum residual limits of veterinary medicinal products in foodstuffs of animal origin. EU Regulation 2377/90. Off. J. Eur. Commun. L224:1-8.

Fagerquist, C. K., A. R. Lightfield, and S. J. Lehotay. 2005. Confirmatory and quantitative analysis of $\beta$-lactam antibiotics in bovine kidney tissue by dispersive solid-phase extraction and liquid chromatography-tandem mass spectrometry. Anal. Chem. $77: 1473-1482$.

Feng, Y., X. Fan, L. Jia, L. Ma, and J. Zhang. 2012a. Simultaneous determination of 14 penicillins and penicilloic acids in milk by UPLC-MS/MS. Chin. J. Anal. Lab. 31:67-70.

Feng, Y., R. Wang, Y. Wang, X. Fan, and J. Zhang. 2012b. Simultaneous determination of penicillin $\mathrm{G}$ and penicilloic acid in milk by UPLC-MS/MS. Chin. Food Sci. Technol. 37:301-304.

Ghidini, S., E. Zanardi, G. Varisco, and R. Chizzolini. 2003. Residues of $\beta$-lactam antibiotics in bovine milk: Confirmatory analysis by liquid chromatography tandem mass spectrometry after microbial assay screening. Food Addit. Contam. 20:528-534.

Goldman, E. 2004. Antibiotic abuse in animal agriculture: Exacerbating drug resistance in human pathogens. Hum. Ecol. Risk Assess. $10: 121-134$

Holstege, D. M., B. Puschner, G. Whitehead, and F. D. Galey. 2002. Screening and mass spectral confirmation of $\beta$-lactam antibiotic residues in milk using LC-MS/MS. J. Agric. Food Chem. 50:406411.

Hou, J. P., and J. W. Poole. 1971. $\beta$-Lactam antibiotics: Their physicochemical properties and biological activities in relation to structure. J. Pharm. Sci. 60:503-532.

Kheirolomoom, A., A. Kazemi-Vaysari, M. Ardjmand, and A. Baradar-Khoshfetrat. 1999. The combined effects of $\mathrm{pH}$ and temperature on penicillin $\mathrm{G}$ decomposition and its stability modeling Process Biochem. 35:205-211.

Kindred, T. P., and W. T. Hubbert. 1993. Residue prevention strategies in the United States. J. Am. Vet. Med. Assoc. 202:46-49.

Kukusamude, C., R. Burakham, O. Chailapakul, and S. Srijaranai. 2012. High performance liquid chromatography for the simultaneous analysis of penicillin residues in beef and milk using ionpaired extraction and binary water-acetonitrile mixture. Talanta 92:38-44.

Lara, F. J., M. del Olmo-Iruela, C. Cruces-Blanco, C. Quesada-Molina, and A. M. García-Campaña. 2012. Advances in the determination of $\beta$-lactam antibiotics by liquid chromatography. Trends Analyt. Chem. 38:52-66.

Liu, C.-J., H. Wang, Z.-X. Du, Y.-B. Jiang, J.-H. Shan, and Y.-H. Cai. 2011. Simultaneous determination of 2 penicillins and their 5 major metabolites in bovine muscle by ultra performance liquid chromatography tandem mass spectrometry. Chin. J. Anal. Chem. 39:617-622.

Marchetti, M., I. Schwaiger, and E. R. Schmid. 2001. Determination of benzylpenicillin, oxacillin, cloxacillin, and dicloxacillin in cows' milk by ion-pair high-performance liquid chromatography after precolumn derivatization. Fresenius J. Anal. Chem. 371:64-67.

Msagati, T. A. M., and M. M. Nindi. 2007. Determination of $\beta$-lactam residues in foodstuffs of animal origin using supported liquid membrane extraction and liquid chromatography-mass spectrometry. Food Chem. 100:836-844.

Page, M. I. 1984. The mechanism of reactions of $\beta$-lactam antibiotics. Acc. Chem. Res. 17:144-151.

Reyns, T., M. Cherlet, S. De Baere, P. De Backer, and S. Croubels. 2008. Rapid method for the quantification of amoxicillin and its 
major metabolites in pig tissues by liquid chromatography-tandem mass spectrometry with emphasis on stability issues. J. Chromatogr. B Analyt. Technol. Biomed. Life Sci. 861:108-116.

Riediker, S., and R. H. Stadler. 2001. Simultaneous determination of five $\beta$-lactam antibiotics in bovine milk using liquid chromatography coupled with electrospray ionization tandem mass spectrometry. Anal. Chem. 73:1614-1621.

Riediker, S., A. Rytz, and R. H. Stadler. 2004. Cold-temperature stability of five $\beta$-lactam antibiotics in bovine milk and milk extracts prepared for liquid chromatography-electrospray ionization tandem mass spectrometry analysis. J. Chromatogr. A 1054:359-363.

Shea, K. M. 2003. Antibiotic resistance: What is the impact of agricultural uses of antibiotics on children's health? Pediatrics 112:253258.

Suwanrumpha, S., and R. B. Freast. 1989. Identification of metabolites of ampicillin using LC/thermospray MS and FAB tandem MS. Biomed. Environ. Mass Spectrom. 18:983-994.

Wang, W., L. Liu, L. Xu, W. Ma, H. Kuang, and C. Xu. 2013. Detection of $\beta$-lactamase residues in milk by sandwich ELISA. Int. J. Environ. Res. Public Health 10:2688-2698.
Xu, Z., H.-Y. Wang, S.-X. Huang, Y.-L. Wei, S.-J. Yao, and Y.-L. Guo. 2010. Determination of $\beta$-lactamase residues in milk using matrix-assisted laser desorption/ionization Fourier transform mass spectrometry. Anal. Chem. 82:2113-2118.

Zhang, X., L. Chen, Y. Xu, H. Wang, Q. Zeng, Q. Zhao, N. Ren, and L. Ding. 2010a. Determination of $\beta$-lactam antibiotics in milk based on magnetic molecularly imprinted polymer extraction coupled with liquid chromatography-tandem mass spectrometry. J. Chromatogr. B Analyt. Technol. Biomed. Life Sci. 878:3421-3426.

Zhang, Y., Y. Jiang, and S. Wang. 2010b. Development of an enzymelinked immunosorbent assay to detect benzylpenicilloic acids, degradation product of penicillin $\mathrm{G}$ in adulterated milk. J. Agric. Food Chem. 58:8171-8175.

Zhu, W., Y. Liu, P. Yuan, J. Guo, J. Yang, W. Wei, and Z. Sun. 2010. Fast determination of $19 \beta$-lactams and metabolites in milk by ultra-performance liquid chromatography-tandem mass spectrometry and dispersion solid-phase extraction. Chin. J. Anal. Lab. 297:29-32. 